\title{
PENGEMBANGAN KAWASAN GEOPARK KALDERA TOBA DI KABUPATEN SAMOSIR Development of The Geopark Kaldera Toba Area in Samosir District
}

\author{
Sahala Fransiskus Marbun ${ }^{1}$, Luthfi Muta'ali ${ }^{2}$, Sudrajat ${ }^{2}$ \\ ${ }^{1}$ Mahasiswa Pascasarjana Geografi, Fakultas Geografi, Universitas Gadjah Mada \\ ${ }^{2}$ Dosen Fakultas Geografi, Universitas Gadjah Mada, Jl. Kaliurang Bulaksumur Yogyakarta \\ Email Korespondensi: sahala.fransiskus.m@mail.ugm.ac.id
}

DOI: $10.31314 /$ jsig.v2i2.281

Abstract - Geopark is an area with boundaries that have been clearly defined and have a large surface area for local economic development. Geopark not only consists of a number of geological diversity that has special interests, scarcity and beauty known as geological heritage, but also cultural diversity and biotic diversity. As one of the districts included in the Toba Caldera Geopark Region, Samosir Regency has a unique location, which is a district where the entire administrative area is the Toba Caldera Geopark Region. This study aims to formulate a strategy to develop Toba Caldera Geopark in Samosir Regency. The method used is descriptive qualitative by using Analysis Hierarchy Process (AHP) analysis techniques. The results showed that the priority strategy for the development of the Toba Caldera Geopark Area in Samosir District was community development, conservation and also economic development. The strategic program that is a priority in the development of the Toba Caldera Geopark Area in Samosir Regency from the aspect of community development is Involving the local community in the preparation of geopark activities programs, Socialization of the concept of geopark to the community, Improvement of geological, biological and cultural education.

Keywords: Geopark, Area Development, AHP

\begin{abstract}
Abstrak - Geopark merupakan sebuah daerah dengan batasan yang sudah ditetapkan dengan jelas dan memiliki kawasan permukaan yang cukup luas untuk pembangunan ekonomi lokal. Geopark tidak hanya terdiri atas sejumlah keragaman geologi yang memiliki kepentingan khusus, kelangkaan dan keindahan yang dikenal dengan warisan geologi, namun juga keragaman budaya dan keragaman biotik. Sebagai salah satu kabupaten yang termasuk ke dalam Kawasan Geopark Kaldera Toba, Kabupaten Samosir memiliki berapa keunikan yaitu merupakan kabupaten yang seluruh wilayah administrasinya merupakan Kawasan Geopark Kaldera Toba. Penelitian ini bertujuan untuk merumuskan strategi pengembangan geopark kaldera toba di Kabupaten Samosir. Metode yang digunakan adalah deskriptif kualitatif dengan memakai teknik analisis Analysis Hierarchy Process (AHP). Hasil penelitian menunjukan bahwa Strategi prioritas pengembangan Kawasan Geopark Kaldera Toba di Kabupaten Samosir adalah pengembangann masyarakat,konservasi dan juga pembangunan ekonomi. Program Strategi yang menjadi prioritas dalam pengembangan Kawasan Geopark Kaldera Toba di Kabupaten Samosir dari aspek pengembangan masyarakat adalah Melibatkan masyarakat setempat dalam penyusunan program-program kegiatan geopark, Sosialisasi konsep geopark kepada masyarakat, Peningkatan pendidikan geologi, hayati, maupan budaya.
\end{abstract}

Kata kunci: Geopark, Pengembangan Wilayah, AHP 


\section{PENDAHULUAN}

Geopark merupakan sebuah daerah dengan batasan yang sudah ditetapkan dengan jelas dan memiliki kawasan permukaan yang cukup luas untuk pembangunan ekonomi lokal. Geopark tidak hanya terdiri atas sejumlah keragaman geologi yang memiliki kepentingan khusus, kelangkaan dan keindahan yang dikenal dengan warisan geologi, namun juga keragaman budaya dan keragaman biotik (Oktariadi, 2018). Geopark sendiri terbagi atas 3 klasifikasi, yaitu geopark berskala global, nasional, dan lokal. Indonesia mempunyai 80 geopark berskala nasional dan empat geopark global, yaitu Geopark Batur-Bali, Geopark Gunung Sewu-Jogjakarta, Geopark Rinjani-Lombok dan Geopark Cileyun-Jawa Timur. Geopark dengan skala lokal 80 destinasi. Sedangkan Geopark dengan skala nasional terdapat 7 destinasi, salah satu diantaranya Kaldera Toba yang terdapat di Sumatra Utara. Menurut KBBI kaldera merupakan kawah gunung berapi yang sangat besar, terjadi karena peledakan atau runtuhnya bagian puncak gunung berapi.

Geopark Kaldera Toba sendiri dikukuhkan sebagai Geopark berskala nasional pada 7 Oktober 2013 dan diresmikan pada 27 Maret 2014 oleh pemerintah Indonesia dengan tema Supervolcano dengan objek utama berupa Kaldera Toba yang terjadi akibat letusan dasyat gunung api jutaan tahu silam. Kawasan geopark Kaldera Toba dikelilingi oleh 7 (tujuh) kabupaten, yaitu Kabupaten Dairi, Kabupaten Humbang Hasudutan, Kabupaten Karo, Kabupaten Simalungun, Kabupaten Tapanuli Utara, Kabupaten Toba Samosir dan Kabupaten Samosir.

Mengacu pada kajian dan penelitian tentang Kaldera Toba dikutip dari kaldera toba geopark, sebaran dan identifikasi singakapan batuan, situs-situs geologi Kaldera Toba dikelompokkan menjadi 4 (empat) geoarea dengan mempertimbangkan kondisi geografisnya, yaitu Kaldera Porsea, Kaldera Haranggaol, Kaldera Sibandang dan Geoarea Samosir. Dimana Geoarea Samosir yang akan menjadi fokus penelitian terletak di daerah administrasi Kabupaten Samosir. Sebagai salah satu kabupaten yang termasuk ke dalam Kawasan Geopark Kaldera Toba, Kabupaten Samosir memiliki berapa keunikan yaitu merupakan kabupaten yang seluruh wilayah administrasinya merupakan Kawasan Geopark Kaldera Toba. Badan Otoritas pengelola Kawasan Geopark mengeluarkan 5 dari 16 geosite yang diajukan untuk mendapat pengakuan dari UNESCO adalah berada di Kabupaten Samosir.

Keunikan geologi, biologi dan budaya yang terdapat di kawasan Danau Kaldera Toba dapat dimanfaatkan sebagai salah satu potensi wisata untuk meningkatkan ekonomi lokal melalui peningkatan pendapatan masyarakat. Sesuai dengan konsep geopark yaitu konservasi, pendidikan dan peningkatan ekonomi lokal maka pengembangan geopark Kaldera Toba harus dimulai dari unsur utama pengelolaan geopark itu sendiri yaitu regulasi kebijakan, infrastruktur, dan peningkatan partisipasi masyarakat. Dari konsep pengelolaan geopark tersebut, penelitian ini akan difokuskan pada strategi pengembangan Geopark Kaldera Toba dengan melihat karakeristik geopark yang ada di Kabupaten Samosir dan perkembangan unsur utama pengelolaan geopark setelah diresmikannya Geopark Kaldera Toba khususnya di Kabupaten Samosir

\section{METODE DAN DATA}

Metode penelitian yang digunakan dalam penelitian ini adalah studi deskriptif dengan pendekatan kualitatif. Penelitian dilakukan di Kabupaten Samosir yang merupakan salah satu dari tujuh kabupaten yang termasuk dalam kawasan Geopark Kaldera Toba.

Berikut informan yang dipilih dalam analisis AHP yaitu:

1. Badan Perencanaan Pembangunan Daerah (BAPPEDA) Kabupaten Samosir.

2. Bupati Kabupaten Samosir

3. Dewan Perwakilan Rakyat Daerah (DPRD) Kabupaten Samosir

4. Ilmuwan/ahli pengembangan geopark

5. Camat setiap Geosite (Sianjur Mulamula, Ronggur Nihuta, Pangururan, Simanindo)

6. Tokoh Masyarakat di Kabupaten Samosir 
Analysis Hierarchy Process (AHP) merupakan salah satu teknik untuk membantu pengambilan keputusan yang komprehensif karena sifatnya yang multi atribut untuk menangani masalah yang kompleks baik aspek kualitatif dan kuantitatif (Mutaali, 2015). AHP ini digunakan untuk menentukan Strategi Pengembangan Geopark Kaldera Toba di Kabupaten Samosir.

\section{HASIL DAN PEMBAHASAN}

Analisis Hierarki Proccess (AHP) digunakan untuk memudahkan dalam pengambilan keputusan terkait Pengembangan Kawasan Geopark Kaldera Toba di Kabupaten dengan melakukan perbandingan berpasangan antar aspek dan antar kriteria. Berdasarkan penjabaran permasalahan dan tujuan dari konsep geopark bagi perkembangan wilayah, maka ditetapkan bahwa hierarki yang akan digunakan dalam analisis hierarki proses (AHP) untuk merumuskan strategi pengembangan Kawasan Geopark Kaldera Toba di Kabupaten Samosir terdiri atas tiga tingkat yaitu:

1) Tujuan :Menentukan strategi pengembangan Kawasan Geopark Kaldera Toba di Kabupaten Samosir.

2) Aspek :Konservasi, Pembangunan Ekonomi, Pengembangan Masyarakat

3) Kriteria :Konservasi (Membuat regulasi kebijakan tentang konservasi, Perawatan situs-situs geologi yang rawan mengalami kerusakan, Pembuatan zonasi cagar alam maupun cagar budaya), Pembangunan Ekonomi (Pembangunan infrastruktur, Pengembangan industri kreatif lokal, membuat kegiatan-kegiatan pariwisata), Pengembangan Masyarakat (Sosialisasi konsep geopark kepada masyarakat, Melibatkan masyarakat setempat dalam penyusunan program-program kegiatan geopark, Peningkatan pendidikan geologi, hayati, maupan budaya).

\section{Hasil Perhitungan Analisis Hierarki Proses}

Penetapan hierarki, selanjutnya dilakukan berbandingan berpasangan untuk menentukan strategi peningkatan manfaat industri semen bagi perkembangan wilayah dalam aspek dan kriteria. Setiap aspek dan kriteria yang telah dibandingkan secara berpasangan menghasilkan nilai (bobot). Semakin tinggi nilai yang diperoleh, maka semakin tinggi aspek dan kriteria dalam strategi peningkatan manfaat. Pengolahan data analisis hierarki proses didasarkan pada pembobotan yang dilakukan oleh 9 informan kunci atau key person. Hasil pembobotan kemudian diolah menggunakan software expert choice v.11. Software ini mempermudah analisis data, karena secara otomatis menghitung inkonsistensi data hasil pembobotan. Berikut disajikan hasil analisis hierarki proses (AHP), aspek dan kriteria:

1. Hasil Perhitungan Aspek: Konservasi, Pembangunan Ekonomi dan Pengembangan Masyarakat

\section{Goal: Strategi Pengembangan Kawasan Geopark Kaldera Toba Di Kabupaten Samosir}

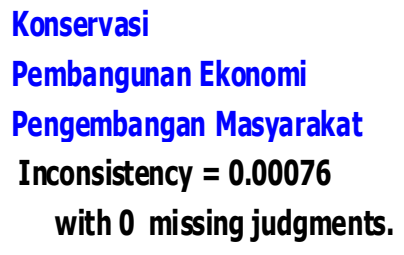

Gambar 1. Stategi Pengembangan Kawasan Geopark Kaldera Toba Di Kabupaten Samosir. (Sumber:

Hasil Analisis Data Primer dengan Expert Choice v.11, 2019)

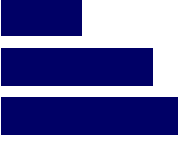


Berdasarkan gambar diatas menunjukkan bahwa aspek pengembangan masyarakat memiliki nilai tertinggi yaitu 43.2\% dibandingkan dengan aspek konservasi dengan nilai 19,6\% dan aspek pembangunan ekonomi dengan nilai 37,2\%. Inkonsistensi data 0,00076 lebih kecil dari 0,1 artinya bahwa data tersebut dianggap valid dan diterima. Hal ini menunjukkan bahwa dalam rencana pengembangan Kawasan Geopark Kaldera Toba di Kabupaten Samosir lebih mengutamakan strategi pengembangan yang difokuskan terhadap pengembangan masyarakat, kemudian aspek pembangunan ekonomi dan konservasi.

Hasil pembobotan ini merupakan representasi dari pandangan responden yang menyatakan bahwa pengembangan Kawasan Geopark Kaldera oba di Kabupaten Samosir mayoritas adalah sektor pengembangan masyarakat perlu menjadi prioritas utama untuk dilakukan. Responden memandang bahwa kegiatan pengembangan yang direncanakan semestinya diutamakan pada pengembangan masyarakat yang ada di Kabupaten Samosir. Hasil pangamatan dilapangan juga menyimpulkan kurangnya pengembangan masyarakat sebagai objek pengembangan geopark terhadap perencanaan pembangunan wilayah di Kabupaten Samosir, sehingga dapat terlihat hasil pembobotan menempatkan aspek pengembangan masyarakat menjadi prioritas dibandingkan dengan aspek pembangunan ekonomi maupun aspek konservasi.

\section{Hasil Perhitungan Perbandingan Berpasangan Kriteria Aspek Konservasi}

Pada aspek konservasi, kriteria yang dibandingkan untuk memperoleh prioritas kriteria yang perlu diutamakan dalam rencana pengembangan Kawasan Geopark Kaldera Toba di Kabupaten adalah membuat regulasi kebijakan tentang konservasi, perawatan situs-situs geologi yang rawan mengalami kerusakan, pembuatan zonasi cagar alam maupun cagar budaya. Adapun hasil pengolahan data hasil pembobotan berdasarkan hasil persepsi gabungan tertera pada gambar dibawah ini.

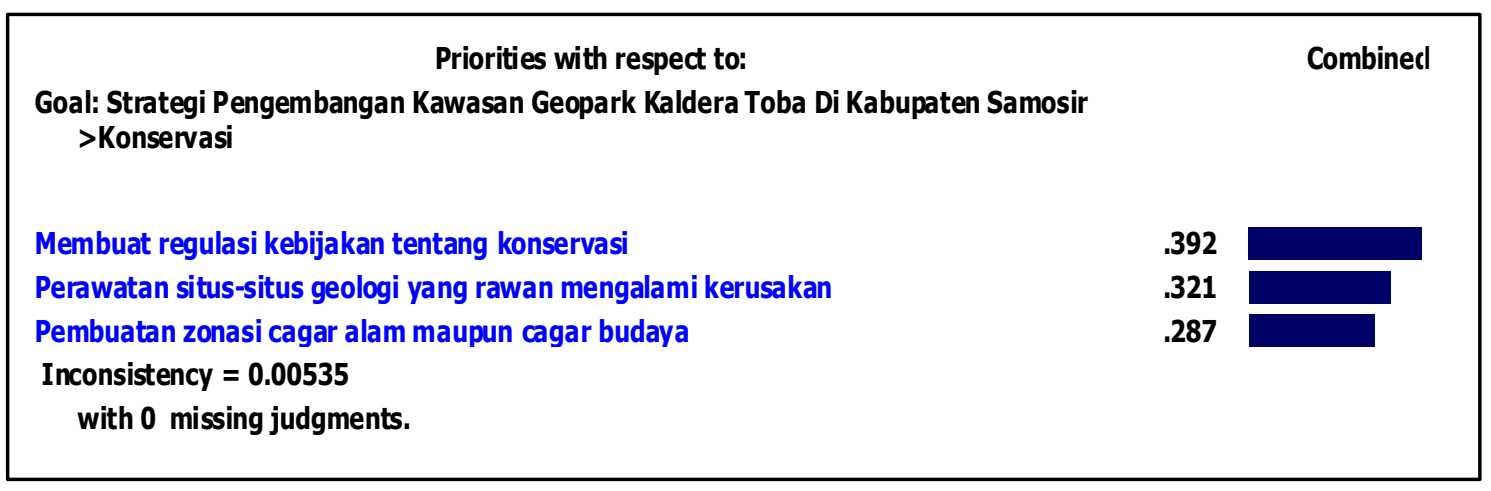

Gambar 2. Stategi Pengembangan Kawasan Geopark Kaldera Toba Di Kabupaten Samosir: Konservasi. (Sumber: Hasil Analisis Data Primer dengan Expert Choice v.11, 2019)

Hasil analisis gambar diatas menunjukan bahwa pada aspek konservasi, prioritas kriteria yang sangat diharapkan dalam rencana pengembangan Kawasan Geopark Kaldera Toba di Kabupaten adalah kriteria membuat regulasi kebijakan tentang konservasi dengan nilai 39,2\%, selanjutnya adalah perawatan situs-situs geologi yang rawan mengalami kerusakan dengan nilai $32.1 \%$ lalu disusul oleh pembuatan zonasi cagar alam maupun cagar budaya dengan nilai $28,7 \%$. Hal ini menjadikan pembuatan regulasi kebijakan tentang konservasi menjadi prioritas utama di aspek konservasi. Inkonsistensi dari hasil analisis adalah 0,00535 kurang dari 0,1 sehingga dapat dikatakan bahwa hasil pembobotan diterima dan tidak perlu dilakukan normalisasi data.

\section{Hasil Perhitungan Perbandingan Berpasangan Kriteria Aspek Pembangunan Ekonomi}

Pada aspek pembangunan ekonomi, kriteria yang dibandingkan untuk memperoleh prioritas kriteria yang perlu diutamakan dalam rencana pengembangan Kawasan Geopark Kaldera Toba di Kabupaten Samosir adalah pembangunan infrastruktur, pengembangan industri 
kreatif lokal, membuat kegiatan-kegiatan pariwisata. Adapun hasil pengolahan data hasil pembobotan berdasarkan persepsi gabungan tertera pada gambar dibawah ini:

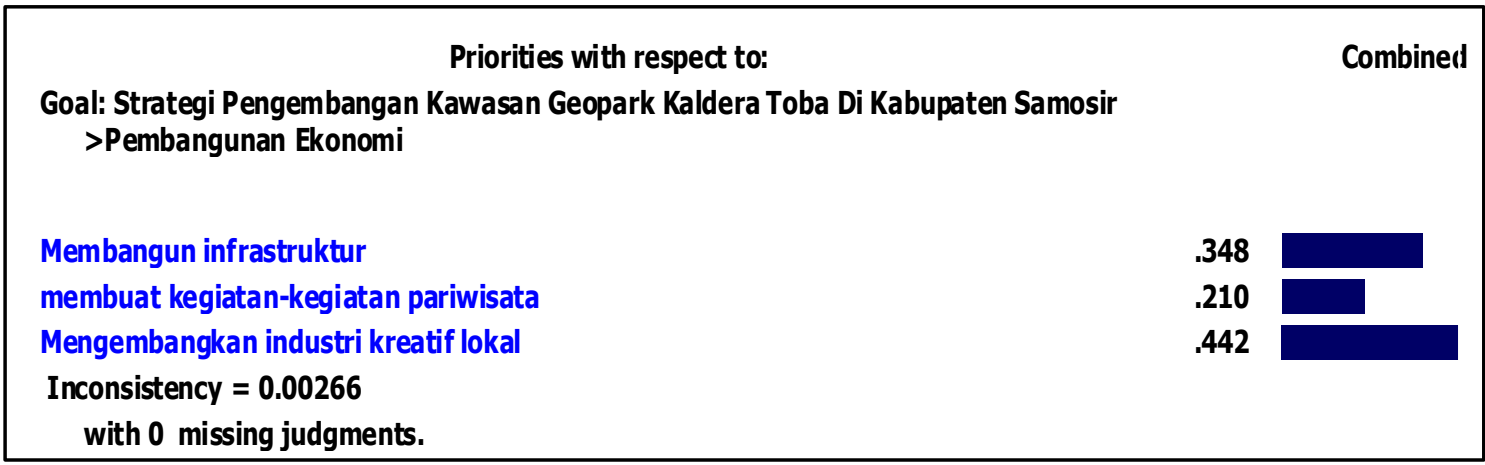

Gambar 3. Stategi Pengembangan Kawasan Geopark Kaldera Toba Di Kabupaten Samosir: Pembangunan Ekonomi. (Sumber: Hasil Analisis Data Primer dengan Expert Choice v.11, 2019)

Hasil analisis pada gambar diatas menunjukan bahwa untuk aspek pembangunan ekonomi urutan prioritas kriteria yang harus diupayakan dalam penyusunan rencana pengembangan Kawasan Geopark Kaldera Toba di Kabupaten Samosir adalah pembangunan infrastruktur dengan nilai $34,8 \%$, pengembangan industri kreatif lokal dengan nilai $44,2 \%$ dan membuat kegiatan-kegiatan pariwisata dengan nilai $21 \%$. Hal ini menjadikan pengembangan industri kreatif lokal menjadi prioritas utama di aspek pembangunan ekonomi ini. Inkonsistensi dari hasil analisis adalah 0,00266 lebih kecil daripada 0,1 sehingga data dapat diterima tanpa perlu dilakukan normalisasi ataupun revisi pendapat.

\section{Hasil Perhitungan Perbandingan Berpasangan Kriteria Aspek Pengembangan Masyarakat}

Pada aspek pengembangan masyarakat, kriteria yang dibandingkan untuk memperoleh prioritas kriteria yang perlu diutamakan dalam rencana pengembangan Kawasan Geopark Kaldera Toba di Kabupaten Samosir adalah sosialisasi konsep geopark kepada masyarakat, melibatkan masyarakat setempat dalam penyusunan program-program kegiatan geopark, peningkatan pendidikan geologi, hayati, maupan budaya. Adapun hasil pengolahan data hasil pembobotan berdasarkan persepsi gabungan tertera pada gambar dibawah ini.

\begin{tabular}{|lc|}
\hline \multicolumn{1}{|c|}{ Priorities with respect to: } & Comb.. \\
$\begin{array}{l}\text { Goal: Strategi Pengembangan Kawasan Geopark Kaldera Toba Di Kabupaten Samosir } \\
\text { >Pengembangan Masyarakat }\end{array}$ & \\
& \\
Sosialisasi konsep geopark kepada masyarakat & .333 \\
Melibatkan masyarakat setempat dalam penyusunan program-program kegiatan geopark & .480 \\
Peningkatan pendidikan warisan geologi, hayati maupun budaya & .187 \\
Inconsistency $=\mathbf{0 . 0 0 7 3 6}$ & \\
with $\mathbf{0}$ missing judgments. & \\
\hline
\end{tabular}

Gambar 4. Stategi Pengembangan Kawasan Geopark Kaldera Toba Di Kabupaten Samosir: Pengembangan Msyarakat. (Sumber: Hasil Analisis Data Primer dengan Expert Choice v.11, 2019)

Hasil analisis menunjukan bahwa untuk aspek pengembangan masyarakat urutan prioritas kriteria yang harus diupayakan dalam penyusunan rencana pengembangan Kawasan Geopark Kaldera Toba di Kabupaten Samosir adalah sosialisasi konsep geopark kepada masyarakat dengan nilai 33,3\%, melibatkan masyarakat setempat dalam penyusunan program-program kegiatan geopark dengan nilai $48 \%$ dan peningkatan pendidikan geologi, hayati, maupan budaya dengan nilai $18,7 \%$. Hal ini menjadikan pelibatan masyarakat setempat dalam 
penyusunan program-program kegiatan geopark menjadi prioritas utama di aspek pengembangan masyarakat ini. Inkonsistensi dari hasil analisis adalah 0,00736 lebih kecil daripada 0,1 sehingga data dapat diterima tanpa perlu dilakukan normalisasi ataupun revisi pendapat.

Adapun rangkuman hasil perhitungan semua kriteria, baik kriteria aspek konservasi, pembangunan ekonomi, dan pengembangan masyarakat dengan berdasarkan persepsi BAPPEDA Kabupaten Samosir, Bupati Kabupaten samosir, DPRD Kab Samosir, Ilmuan/Akademisi, Camat Sianjur Mula-mula, Camat Pangururan, Camat Ronggur Ni Huta, Camat Simanindo, dan juga tokoh masyarakat dapat dilihat pada tabel dibawah ini:

Tabel 1. Hasil Menentukan Strategi Dengan AHP (Sumber: Hasil Analisis Data Primer, 2019)

\begin{tabular}{|c|c|c|c|c|}
\hline No & Aspek & $\begin{array}{l}\text { Hasil } \\
\text { AHP }\end{array}$ & Strategi & Program Strategi \\
\hline 1 & Konservasi & $19,6 \%$ & \multirow{3}{*}{$\begin{array}{l}\text { Pengembangan } \\
\text { Masyarakat }\end{array}$} & $\begin{array}{l}\text { Melibatkan masyarakat } \\
\text { setempat dalam penyusunan } \\
\text { program-program kegiatan } \\
\text { geopark }\end{array}$ \\
\hline 2 & Pembangunan Ekonomi & $37,2 \%$ & & $\begin{array}{l}\text { 2. Sosialisasi konsep geopark } \\
\text { kepada masyarakat }\end{array}$ \\
\hline 3 & Pengembangan Masyarakat & $43,2 \%$ & & $\begin{array}{l}\text { 3. Peningkatan pendidikan } \\
\text { geologi, hayati, maupan } \\
\text { budaya }\end{array}$ \\
\hline
\end{tabular}

Berdasarkan tabel diatas hasil analisis berpasangan untuk strategi pengembangan Kawasan Geopark Kaldera Toba di Kabupaten Samosir yang dipilih oleh responden adalah strategi pengembangan masyarakat. Hal ini menunjukan bahwa strategi pengembangan Kawasan Geopark Kaldera Toba di Kabupaten Samosir lebih mengutamakan pengembangan masyarakat dengan programstrategi prioritas melibatkan masyarakat setempat dalam penyusunan programprogram kegiatan geopark, sosialisasi konsep geopark kepada masyarakat dan juga peningkatan pendidikan geologi, hayati, maupan budaya.

\section{KESIMPULAN}

Strategi prioritas pengembangan Kawasan Geopark Kaldera Toba di Kabupaten Samosir adalah pengembangan masyarakat,konservasi dan juga pembangunan ekonomi. Program Strategi yang menjadi prioritas dalam pengembangan Kawasan Geopark Kaldera Toba di Kabupaten Samosir adalah Melibatkan masyarakat setempat dalam penyusunan programprogram kegiatan geopark, Sosialisasi konsep geopark kepada masyarakat, Peningkatan pendidikan geologi, hayati, maupan budaya.

\section{DAFTAR PUSTAKA}

Arif, Ahmad, 2014., Toba Mengubah Dunia., Penerbit Buku Kompas., Jakarta.

Arikunto, S. (1989). Prosedur Penelitian Suatu Pendekatan Praktek. Rineka Cipta. Jakarta.

Batten, T.R. 1967. Communities and Their Development. London : Oxford University Press.

Conyers,Diana. 1991. Perencanaan Sosial di Dunia Ketiga. Yogyakarta: Gadjah Mada University Press.

David, 1980, Using the analytic hierarchy process to select investment in a heterogenous environment, 8: 157-162

Oktariadi, Oki., 2014., Geopark dan Penataan Ruang., Jakarta: Badan Geologi Kementrian Energi dan Sumber Daya Mineral.

UNESCO., 2004., Guidelines and Criteria for National Geopark seeking Unesco's asitance to join the Global Geoparks Network (GGN)., France., Division of Ecological and Earth Sciences UNESCO 